\title{
Pengembangan Metode Evaluasi Komitmen Ketahanan Pangan Dan Gizi Pemerintah Daerah Provinsi Di Indonesia
}

\section{Development of Evaluation Method for Commitment towards Food and Nutrition Security in the Provincial Government in Indonesia}

\author{
Novfitri Syuryadi $^{* 1}$, Drajat Martianto ${ }^{2}$, Dadang Sukandar ${ }^{3}$
}

\begin{abstract}
ABSTRAK
Latar Belakang: Metode evaluasi komitmen pemerintah daerah provinsi dalam pembangunan ketahanan pangan dan gizi saat ini belum tersedia. Index yang mengukur komitmen pemerintah terhadap ketahanan pangan dan gizi secara nasional adalah $\mathrm{HANCl}$. Oleh karena itu, studi ini bertujuan untuk mengembangkan metode evaluasi komitmen pemerintah daerah provinsi dalam pembangunan ketahanan pangan dan gizi.

Tujuan: Penelitian ini bertujuan untuk mengembangkan metode evaluasi komitmen pemerintah daerah provinsi dalam pengembangan ketahanan pangan dan gizi.

Metode: Desain penelitian ini adalah cross-sectional study dengan menggunakan data sekunder yang mengacu pada pengukuran $\mathrm{HANCl}$. Tahap penelitian terdiri dari identifikasi indikator potensial, seleksi calon indikator secara kualitatif, perhitungan skor menggunakan metode scoring, dan aplikasi metode pada provinsi di Indonesia.

Hasil: Hasil menunjukkan shortlist 42 indikator komitmen ketahanan pangan dan gizi dan skor agregat provinsi. Berdasarkan hasil penelitian diketahui bahwa hanya $2,9 \%$ provinsi yang memiliki komitmen tinggi dan $17,6 \%$ provinsi memiliki tingkat komitmen rendah. Provinsi Jawa Timur berada pada peringkat pertama sedangkan peringkat terakhir ditempati oleh Provinsi Nusa Tenggara Timur. Komitmen politik yang rendah dapat menyebabkan rendahnya prioritas intervensi pangan dan gizi. Pemerintah perlu membuat peraturan/kebijakan dan menyiapkan anggaran yang memadai untuk program pangan dan gizi secara spesifik maupun sensitif.

Kesimpulan: Pengembangan metode telah relevan digunakan untuk melihat komitmen pemerintah daerah provinsi. Pemerintah perlu meningkatkan upaya berupa pembuatan peraturan dan kebijakan serta anggaran untuk penanganan masalah pangan dan gizi.
\end{abstract}

Kata kunci: indikator komitmen, ketahanan pangan dan gizi, komitmen politik

\section{ABSTRACT}

Background: Methods of evaluation of the regional government's commitment in the development of food and nutrition security are not yet available. The index that measures the government's commitment to national food and nutrition security is $\mathrm{HANCl}$. Therefore, this study aimed to develop a method of evaluating the commitment of the regional government in the development of food and nutrition security.

Objectives: This study aimed to develop a method of evaluating the commitment of regional government in the development of food and nutrition security.

Methods: The design of this study was a cross-sectional study using secondary data that refers to HANCI measurements. This research stage consisted of identification of potential indicators, qualitative selection of candidate indicator, assessment of indicator used the scoring method, and applied the method to provinces in Indonesia.

Results: The result showed shortlist of 42 commitment indicators of food and nutrition security and aggregate score of provinces. Only $2.9 \%$ of provinces had high commitment and $17.6 \%$ of provinces with low commitment level. Highest rank was achieved by East Java Province and the lowest rank was East Nusa Tenggara Province. Low political commitment could lead to low priority of food and nutrition interventions. The government was in need to make regulations/policies and prepare adequate budgets for specific and sensitive food and nutrition programs.

Conclusions: Development of this evaluation method is relevant to show the commitment of the regional government. The government needs to improve efforts to address problems of food and nutrition.

Keywords: commitment indicator, food and nutrition security, political commitment. 


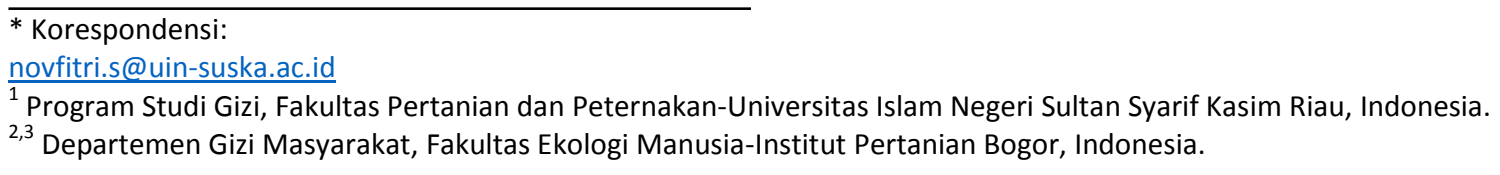

\section{PENDAHULUAN}

Ketahanan pangan dan gizi merupakan suatu hal yang kompleks yang menghubungkan antara pertanian, pangan, gizi, kesehatan, dan sistem lingkungan. ${ }^{1}$ Ketahanan pangan dan gizi harus memenuhi tiga aspek utama yaitu ketersediaan, akses (fisik dan ekonomi), dan pemanfaatan atau konsumsi. Upaya evaluasi ketahanan pangan dan gizi terus dilakukan melalui pengembangan indeks seperti FAO index, Global Hunger Index (GHI), Global Food Security Index (GFSI), Food Security and Vulnerability Atlas (FSVA), Rice Bowl Index, Hunger and Nutrition Security Index ( $\mathrm{HANCl})$, dan sebagainya. Masing-masing indeks memiliki karakteristik yang berbeda. $F A O$ index dan $\mathrm{GHI}$ mengukur kelaparan dunia, FSVA memetakan kerawanan pangan di Indonesia dengan skala wilayah pedesaan, GFSI mengukur ketahanan pangan dan gizi, dan $\mathrm{HANCl}$ mengukur komitmen tiap negara terhadap pangan dan gizi. ${ }^{2-5}$

FAO menyatakan bahwa evaluasi ketahanan pangan dan gizi dapat menggunakan tiga indikator yaitu indikator struktural, proses, dan outcome. Indikator struktural ketahanan pangan dan gizi menggambarkan komitmen suatu negara atau provinsi untuk menangani permasalahan ketahanan pangan dan gizi. ${ }^{6}$ Mayoritas indeks mengevaluasi ketahanan pangan dan gizi dari segi outcome kecuali $\mathrm{HANCl}$ yang mengevaluasi komitmen pemerintah terhadap penanganan masalah pangan dan gizi.

Komitmen pemerintah sangat penting untuk pembangunan ketahanan pangan dan gizi. Komitmen pemerintah terdiri dari peraturan dan kebijakan yang dibangun dan diproses untuk diimplementasikan dalam bentuk program serta memiliki anggaran dalam pelaksanaannya. $^{2,7,8} \mathrm{HANCl}$ dapat mengevaluasi komitmen suatu negara namun kurang relevan jika diimplementasikan ke wilayah regional. Ukuran evaluasi dalam $\mathrm{HANCl}$ bersifat global dan terdapat beberapa komponen penilaian yang tidak dapat diaplikasikan untuk wilayah provinsi. HANCI perlu dikembangkan agar dapat mengevaluasi komitmen pemerintah daerah terutama untuk negara yang menganut sistem pemerintahan desentralisasi seperti Indonesia. Desentralisasi menyebabkan tiap daerah memiliki hak otonomi untuk mengatur urusan dearahnya termasuk dalam pembangunan ketahanan pangan dan gizi. ${ }^{9,10} \mathrm{Hal}$ ini menyebabkan komitmen pemerintah daerah akan berimplikasi terhadap implementasi suatu program termasuk program pangan dan gizi. ${ }^{11,12}$ Oleh karena itu, dibutuhkan suatu pengembangan metode dengan indikator yang mampu mengukur komitmen politik pemerintah yang dalam studi ini fokus pada pemerintah daerah provinsi dalam pembangunan ketahanan pangan dan gizi.

\begin{abstract}
Penelitian ini bertujuan untuk mengembangkan metode evaluasi komitmen pemerintah daerah provinsi di Indonesia dalam pembangunan ketahanan pangan dan gizi. Hasil evaluasi ini dapat digunakan untuk mengetahui peringkat atau posisi setiap provinsi terkait komitmennya dalam pembangunan ketahanan pangan dan gizi, sekaligus dapat digunakan sebagai instrumen evaluasi dan tolak ukur apresiasi bagi pemerintah pusat untuk pembangunan ketahanan pangan dan gizi daerah.
\end{abstract}

\section{METODE}

\section{Desain, tempat, dan waktu}

Penelitian ini menggunakan desain crosssectional study. Pengambilan data dilakukan pada bulan April sampai September 2017. Penelitian dilaksanakan di Institut Pertanian Bogor, Bogor.

\section{Jenis dan cara pengumpulan data}

Jenis data yang digunakan adalah data sekunder yang terdiri dari data peraturan perundangundangan/kebijakan dan data anggaran terkait ketahanan pangan dan gizi provinsi di Indonesia. Data peraturan dan kebijakan yang digunakan adalah data 5 tahun terakhir (2010-2015) yang terdiri dari peraturan daerah sampai dengan surat keputusan gubernur gubernur. Data diperoleh dari website Kementerian Dalam Negeri (jdih kemendagri) dan dilengkapi dengan peraturan yang ada di website biro hukum masingmasing provinsi. Data anggaran diperoleh dari anggaran rencana pembangunan jangka menengah daerah tahun 2016 di website resmi masing-masing provinsi.

\section{Pengolahan dan analisis data}

Pengolahan dan analisis data menggunakan Microsoft Excell 2010 dan program SPSS versi 16.0. Data kualitatif yang digunakan dikuantifikasi dengan metode scoring dengan pembobotan tiap indikator dianggap sama. Data hasil scoring dianalisis secara deskriptif.

\section{Tahapan penelitian}

1. Identifikasi calon indikator potensial

Tahap awal penelitian ini adalah mengidentifikasi calon indikator komitmen ketahanan pangan dan gizi yang merujuk pada indikator FAO (11 indikator IBSA), HANCI (22 indikator), RPJMN (27 indikator), RANPG (25 indikator), KS-RANPG (21 indikator), dan KUKP (12 indikator). Tahapan ini menghasilkan longlist 118 calon indikator.

2. Seleksi calon indikator secara kualitatif Longlist calon indikator diseleksi secara kualitatif yaitu harus sesuai dengan konsep ketahanan pangan dan gizi (ketersediaan, akses, dan pemanfaatan), tidak serupa (redundant), dan calon 
indikator tersedia dalam data di tingkat provinsi serta dimensi dalam HANCl (peraturan/kebijakan dan anggaran). Seleksi ini menghasilkan 42 indikator.

3. Perhitungan skor

Skor indikator peraturan/kebijakan diberikan nilai 0 jika tidak terdapat peraturan/kebijakan terkait dan nilai 4 jika terdapat peraturan/kebijakan terkait. Tidak terdapat acuan baku dalam penilaian peraturan/kebijakan daerah terkait ketahanan pangan dan gizi. Oleh karena itu peneliti melakukan penyesuaian untuk menyamakan proporsi nilai minimum dan maksimum dari indikator peraturan/kebijakan dan anggaran. Skor indikator anggaran mengacu pada metode $\mathrm{HANCl}$ yaitu skor anggaran merupakan persentase perbandingan terhadap APBN sehingga pada penelitian ini skor anggaran menggunakan data persentase tiap anggaran dibandingkan dengan total APBD tahun 2016 dan dihitung menggunakan nilai mean dan standar deviasi masing-masing indikator. Skor minimum yang diperoleh dari seluruh indikator adalah 0 sedangkan maksimum adalah 168 (perkalian jumlah skor maksimum dengan jumlah shortlist indikator). Skor tiap provinsi selanjutnya dicari rataan dan dikonversi ke dalam skor 0-100. Cara pemberian skor dapat dilihat pada Tabel 1.

4. Aplikasi metode pada provinsi di Indonesia Tahapan terakhir adalah mengaplikasikan metode yang dikembangakan. Pada tahapan ini dilihat peringkat komitmen ketahanan pangan dan gizi berdasarkan skor yang diperoleh dari tiap provinsi.

Tabel 1. Pemberian skor indikator

\begin{tabular}{ll}
\hline \multicolumn{1}{c}{ Indikator dalam dimensi } & Skor \\
\hline Peraturan/kebijakan & $0=$ tidak ada peraturan \\
& $4=$ ada peraturan \\
Anggaran pemerintah & Anggaran program terhadap total APBD (\%) kemudian menggunakan mean \pm SD \\
& $0=$ tidak ada anggaran \\
1 & $=X<$ mean $-1.5 S D$ \\
2 & $=$ mean $-1.5 S D \leq X<$ mean $-0 S D$ \\
3 & $=$ mean $-0 S D \leq X<$ mean $+1 S D$ \\
4 & $=X \geq$ mean $+1 S D$ \\
\hline
\end{tabular}

\section{HASIL DAN PEMBAHASAN}

\section{Indikator Komitmen Ketahanan Pangan dan Gizi}

Indikator komitmen ketahanan pangan dan gizi ini dibuat untuk memenuhi tujuan dari ketahanan pangan dan gizi. Menurut Peraturan Pemerintah No 17 Tahun 2015, ketahanan pangan dan gizi adalah kondisi terpenuhinya pangan dan gizi dari cakupan negara sampai individu yang tercermin dari ketersediaan pangan yang cukup baik jumlah maupun kualitasnya, aman, beragam, memenuhi kebutuhan gizi, merata serta terjangkau dan tidak bertentangan dengan agama, kepercayaan, dan budaya untuk mencapai status gizi normal demi hidup yang sehat, aktif dan produktif secara berkelanjutan.

Longlist calon indikator komitmen ketahanan pangan dan gizi yang telah diseleksi menghasilkan shortlist 42 indikator komitmen ketahanan pangan dan gizi. Indikator ini terdiri dari 13 indikator dalam pilar ketersediaan, 22 indikator dalam pilar akses, dan 7 indikator dalam pilar pemanfaatan. Data indikator komitmen ketahanan pangan dan gizi dapat dilihat pada Tabel 2.

Indikator terpilih kemudian dilakukan uji reliabilitas untuk menentukan konsistensi hasil pengukuran indikator. Ukuran reliabilitas pada umumnya menggunakan Cronbach's alpha. Nilai cut off Cronbach's alpha pada penelitian ini mengacu pada nilai cut off Cronbach's alpha HANCl yaitu 0,7. Berdasarkan hasil penelitian, nilai Cronbach's alpha yang diperoleh dari SPSS adalah 0,848 dan lebih besar dari nilai cut off. Hal ini menunjukkan bahwa indikator yang digunakan telah reliabel. Uji validitas tidak dilakukan dalam penelitian ini karena data yang digunakan telah valid dan digunakan oleh instansi pemerintah yang berwenang.

\section{Peringkat Provinsi dalam Komitmen Ketahanan Pangan dan Gizi}

Pengembangan indikator komitmen diaplikasikan untuk melihat peringkat provinsi dalam komitmen ketahanan pangan dan gizi. Peringkat komitmen pemerintah daerah provinsi dalam pembangunan ketahanan pangan dan gizi diperoleh dari skor agregat indikator. Skor agregat indikator dikonversi ke dalam range 0-100 untuk memudahkan interpretasi hasil. Berikut notasi matematika yang digunakan:

$$
y=a / x \times b
$$

keterangan:

$y=$ agregat skor provinsi $x$ dalam rentang 0-100

$\mathrm{a}=$ total skor indikator

$x=$ total skor maksimal

$\mathrm{b}=$ nilai maksimum konversi

Hasil skor ini dikelompokkan berdasarkan tingkat komitmen rendah, sedang, dan tinggi dengan menggunakan rumus mean \pm SD (Tabel 3). Skor agregat indikator komitmen ketahanan pangan dan gizi dan kategori tingkat komitmen pembangunan ketahanan pangan dan gizi pemerintah daerah provinsi dalam dilihat pada Tabel 4. 
Tabel 2 Indikator komitmen berdasarkan konsep ketahanan pangan dan gizi

\begin{tabular}{|c|c|c|c|}
\hline Aspek & Pilar KPG & Dimensi & Indikator \\
\hline \multirow[t]{23}{*}{ Pangan } & Ketersediaan & Peraturan / kebijakan & Peningkatan produksi pertanian \\
\hline & & & Hak jaminan sosial \\
\hline & & & Diversifikasi tanaman pangan \\
\hline & & & Penguatan cadangan pangan pemerintah \\
\hline & & & Penyediaan pangan berbasis sumberdaya lokal \\
\hline & & Anggaran pemerintah & Anggaran program peningkatan produksi pertanian \\
\hline & & & Anggaran program jaminan sosial \\
\hline & & & Anggaran cadangan pangan pemerintah \\
\hline & & & $\begin{array}{l}\text { Anggaran program diversifikasi pangan berbasis sumberdaya } \\
\text { lokal }\end{array}$ \\
\hline & Akses & Peraturan / kebijakan & Peningkatan sistem distribusi pangan \\
\hline & & & Stabilitas pasokan dan harga pangan \\
\hline & & & Perlindungan dan kesejahteraan petani \\
\hline & & & Subsidi/bantuan pangan \\
\hline & & & Akses dan riset penyuluhan pertanian \\
\hline & & & $\begin{array}{l}\text { Penguatan kelembagaan pangan dan gizi } \\
\text { Pemberdayaan masyarakat berpenghasilan rendah. }\end{array}$ \\
\hline & & Anggaran pemerintah & Anggaran distribusi pangan \\
\hline & & & Anggaran program kesejahteraan petani \\
\hline & & & Anggaran subsidi pangan \\
\hline & & & Anggaran riset penyuluhan pertanian \\
\hline & & & $\begin{array}{l}\text { Anggaran program pemberdayaan masyarakat berpenghasilan } \\
\text { rendah }\end{array}$ \\
\hline & Pemanfaatan & Peraturan / kebijakan & Diversifikasi konsumsi pangan \\
\hline & & & Peningkatan pengawasan mutu dan keamanan pangan \\
\hline & & Anggaran pemerintah & Anggaran program pengawasan mutu dan keamanan pangan \\
\hline \multirow[t]{11}{*}{ Gizi } & Ketersediaan & Peraturan / kebijakan & Kebijakan/strategi gizi daerah \\
\hline & & & Survei gizi daerah \\
\hline & & Anggaran pemerintah & Anggaran program survei gizi daerah \\
\hline & & & $\begin{array}{l}\text { Anggaran penyediaan alat-alat kesehatan dan pelatihan tenaga } \\
\text { kesehatan }\end{array}$ \\
\hline & Akces & & Peningkatan jaminan pelayanan kesehatan \\
\hline & & Peraturan / kebijakan & $\begin{array}{l}\text { Pengendalian penyakit menular dan penyakit tidak menular } \\
\text { (PTM) }\end{array}$ \\
\hline & & & MP-ASI \\
\hline & & & Pemberian mikronutrien \\
\hline & & & Akses air minum dan sanitasi \\
\hline & & Anggaran pemerintah & Anggaran program jaminan pelayanan kesehatan \\
\hline & & & $\begin{array}{l}\text { Anggaran program pengendalian penyakit menular dan tidak } \\
\text { menular }\end{array}$ \\
\hline
\end{tabular}




Aspek Pilar KPG DImensi Indikator

Pemanfaatan Peraturan / kebijakan

Anggaran pemerintah

Anggaran program MP-ASI

\section{Anggaran program pemberian mikronutrien}

Anggaran pembangunan penyediaan air minum dan sarana prasarana dasar sanitasi Percepatan perbaikan status gizi masyarakat

ASI ekslusif dan inisiasi menyusui dini

Perbaikan status gizi masyarakat

ASI ekslusif
Hasil skor menunjukkan bahwa dari 34 provinsi di Indonesia, hanya $2,9 \%$ provinsi yang memiliki komitmen tinggi, $17,6 \%$ provinsi yang memiliki tingkat komitmen rendah, dan $79,5 \%$ provinsi memiliki komitmen sedang. Berdasarkan agregat tersebut diketahui bahwa peringkat pertama dalam komitmen pembangunan ketahanan pangan dan gizi diraih oleh Provinsi Jawa Timur dengan nilai 69 diikuti oleh Daerah Istimewa Yogyakarta, Jawa Barat, dan Jambi. Ibukota Indonesia yaitu Provinsi DKI Jakarta berada pada peringkat 12 dengan tingkat komitmen sedang. Peringkat terakhir diraih oleh Provinsi Nusa Tenggara Timur (NTT) dengan nilai 21. Provinsi Kalimantan Utara (Kaltara) yang merupakan provinsi ke-34 di Indonesia berada pada peringkat 33, lebih baik daripada Provinsi NTT. Provinsi Kaltara merupakan provinsi baru dan secara resmi aktif sejak tahun 2013. Hal ini dapat menjadi penyebab masih sedikitnya data peraturan yang tersedia di Provinsi Kaltara sehingga dalam komitmen pembangunan ketahanan pangan dan gizi, Kaltara masih tertinggal dari provinsi lainnya, meski lebih baik dari provinsi NTT.

Tabel 3 Pengkategorian tingkat komitmen pemerintah daerah provinsi

\begin{tabular}{clll}
\hline No & Kategori & \multicolumn{1}{c}{ Skor } & Interval \\
\hline 1 & Rendah & $\mathrm{X}<$ mean $-\mathrm{SD}$ & $\mathrm{X}<36$ \\
2 & Sedang & $\begin{array}{l}\text { mean }-\mathrm{SD} \leq \mathrm{X} \leq \\
\text { mean }+\mathrm{SD}\end{array}$ & $36 \leq \mathrm{X} \leq 61$ \\
& & $\mathrm{X}>$ mean $+\mathrm{SD}$ & $\mathrm{X}>61$ \\
\hline
\end{tabular}

Tabel 4 Peringkat, skor, dan kategori komitmen provinsi

\begin{tabular}{clclclll}
\hline Peringkat & Provinsi & Skor & Kategori & Peringkat & Provinsi & Skor & Kategori \\
\hline 1 & Jatim & 69 & Tinggi & 18 & Lampung & 54 & Sedang \\
2 & DIY & 61 & Sedang & 19 & Aceh & 52 & Sedang \\
3 & Jabar & 61 & Sedang & 20 & KepBabel & 52 & Sedang \\
4 & Jambi & 61 & Sedang & 21 & Sulbar & 49 & Sedang \\
5 & Gorontalo & 60 & Sedang & 22 & NTB & 48 & Sedang \\
6 & Kaltim & 60 & Sedang & 23 & Banten & 48 & Sedang \\
7 & Sumsel & 60 & Sedang & 24 & PapuaBarat & 46 & Sedang \\
8 & Sulteng & 59 & Sedang & 25 & Kalteng & 40 & Sedang \\
9 & Kalsel & 58 & Sedang & 26 & Bali & 40 & Sedang \\
10 & Sulsel & 58 & Sedang & 27 & Sulut & 38 & Sedang \\
11 & Sumbar & 57 & Sedang & 28 & Papua & 37 & Sedang \\
12 & DKIJakarta & 55 & Sedang & 29 & Sumut & 35 & Rendah \\
13 & Kepri & 55 & Sedang & 30 & Kalbar & 30 & Rendah \\
14 & Maluku & 55 & Sedang & 31 & Sultra & 27 & Rendah \\
15 & Riau & 55 & Sedang & 32 & Malut & 25 & Rendah \\
16 & Bengkulu & 54 & Sedang & 33 & Kaltara & 24 & Rendah \\
17 & Jateng & 54 & Sedang & 34 & NTT & 21 & Rendah \\
\hline
\end{tabular}

Berdasarkan pilar ketahanan pangan dan gizi, diketahui bahwa Provinsi Jawa Timur sebagai provinsi dengan peringkat pertama komitmen ketahanan pangan dan gizi memiliki kekuatan di ketiga pilar yaitu pilar ketersediaan, akses, dan pemanfaatan. Provinsi NTT yang berada di peringkat terakhir memiliki kelemahan dalam komitmen akses dan pemanfaatan, sedangkan 
pada pilar ketersediaan sedikit lebih baik dibandingkan kedua pilar lainnya.

Provinsi Jawa Timur mengalami peningkatan upaya penanganan masalah kerawanan pangan. Menurut FSVA tahun 2009, Provinsi Jawa Timur tergolong dalam wilayah sangat rentan pangan. Selama tahun 2010-2014 pemerintah daerah Jawa Timur terus melakukan upaya penanganan masalah kerawanan pangan sehingga selama periode ini masalah kerawanan pangan wilayah teratasi sebesar 60,48 persen. Ditinjau dari pilar ketersediaan pangan, Jawa Timur termasuk provinsi yang mengalami surplus produksi serealia. ${ }^{13}$

Provinsi Jawa Timur dengan peringkat komitmen tertinggi memiliki peraturan dan kebijakan yang baik hampir di seluruh indikator komitmen ketahanan pangan dan gizi. Ditinjau dari dimensi anggaran, Provinsi Jawa Timur belum memiliki anggaran yang cukup besar dalam pembangunan ketahanan pangan dan gizi. Hal ini ditunjukkan dari hasil penilaian komitmen Jawa Timur yang hanya mencapai skor 69 . Meskipun Provinsi Jawa Timur memiliki komitmen yang relatif tinggi namun masih diperlukan peningkatan komitmen terutama agar komitmen yang tertulis dalam dokumen pembangunan dapat diimplementasikan menjadi program kerja.

Provinsi NTT dengan peringkat terakhir menunjukkan komitmen dari segi peraturan/kebijakan maupun anggaran masih tergolong rendah. Indikator dari dimensi peraturan/kebijakan ketahanan pangan dan gizi yang dimiliki oleh Provinsi NTT hanya tentang peningkatan produksi pertanian, kebijakan/strategi gizi daerah, serta akses air minum dan sanitasi disertai dengan anggarannya. Meskipun tidak terdapat peraturan/kebijakan di tingkat provinsi namun terdapat anggaran yang cukup untuk program jaminan sosial, cadangan pangan, akses dan riset penyuluhan pertanian, jaminan kesehatan, dan pengendalian penyakit menular maupun tidak menular.

Komitmen pemerintah daerah provinsi NTT yang masih tergolong rendah dapat berimplikasi terhadap masih tingginya masalah pangan dan gizi di wilayah tersebut. Permasalahan pangan dan gizi di Provinsi NTT ditunjukkan dengan tingkat kerawanan pangan yang tinggi $(60 \%$ kabupaten NTT rentan terhadap kerawanan pangan) dan prevalensi gizi kurang tertinggi di Indonesia (stunting 51,7\%, wasting 15,4\%, dan underweight $33,1 \%) .{ }^{14}$ Provinsi NTT juga memiliki 44,90 persen desa yang berada pada kondisi sangat rentan dan rentan pangan. ${ }^{15}$ Permasalahan ketahanan pangan dan gizi di Provinsi NTT membutuhkan upaya advokasi dari pihak pemerintah daerah sehingga peran gizi tidak sekedar dianggap sebagai output namun juga sebagai input seperti salah satu faktor penyebab kemiskinan. ${ }^{16}$ Oleh karena itu diperlukan peningkatan komitmen pemerintah daerah provinsi NTT untuk penanganan masalah ketahanan pangan dan gizi dalam bentuk peraturan/kebijakan maupun anggaran program untuk merealisasikan program kerja.

Komitmen politik yang rendah menjadi penyebab rendahnya prioritas intervensi pangan dan gizi oleh pemerintah. Pemerintah perlu membuat peraturan/kebijakan dan menyiapkan anggaran yang memadai untuk program pangan dan gizi secara spesifik maupun sensitif. serta memprioritaskan upaya penanganan masalah pangan dan gizi sesuai dengan permasalahan masing-masing daerah. Masyarakat sipil dapat memantau kemajuan program pemerintah dalam penanganan permasalahan pangan dan gizi. ${ }^{17-20}$

\section{KESIMPULAN}

Pengembangan metode evaluasi komitmen ketahanan pangan dan gizi telah relevan digunakan untuk melihat komitmen pemerintah daerah provinsi. $\mathrm{HANCl}$ memiliki ruang lingkup nasional sedangkan hasil penelitian ini dapat mengevaluasi komitmen pemerintah daerah provinsi. Hasil penelitian menunjukkan hanya $2,9 \%$ provinsi yang memiliki komitmen tinggi, 17,6\% provinsi yang memiliki tingkat komitmen rendah, sedangkan $79,5 \%$ memiliki komitmen sedang. Komitmen pemerintah daerah provinsi dalam pembangunan ketahanan pangan dan gizi perlu ditingkatkan melalui upaya pembuatan peraturan dan kebijakan serta anggaran untuk penanganan masalah pangan dan gizi. Penelitian ini menghasilkan komitmen yang bersifat relatif sehingga diperlukan penelitian lanjutan untuk menentukan skor yang menghasilkan komitmen mutlak untuk melihat konsistensi dari penilaian relatif yang dilakukan. Penelitian lanjutan perlu dilakukan untuk melihat komitmen pemerintah daerah dalam ruang lingkup kabupaten agar permasalahan komitmen ketahanan pangan dan gizi dapat diatasi secara menyeluruh.

\section{ACKNOWLEDGEMENT}

Penulis mengucapkan terimakasih kepada Kementerian Dalam Negeri dan para dosen pembimbing atas arahan dan bimbingannya.

\section{REFERENS}

1. Hammond, R. A. \& Dubé, L. A systems science perspective and transdisciplinary models for food and nutrition security. Proc. Natl. Acad. Sci. U. S. A. 109, 12356-12363 (2012).

2. Masset, E. A review of hunger indices and methods to monitor country commitment to fighting hunger. Food Policy 36, S102-S108 (2011).

3. Purwantini, T. B. Pendekatan Rawan Pangan dan Gizi: Besaran, Karakteristik, dan Penyebabnya. Forum Penelit. Agro Ekon. 32, 1 (2016).

4. Maricic, M., Bulajic, M., Dobrota, M. \& Jeremic, V. Redesigning the global food security index: A multivariate composite I-Distance indicator approach. Int. J. Food Agric. 4, 69-86 (2016).

5. Lintelo, D. \& Lakshman, W. D. The Hunger and Nutrition Commitment Index (HANCl 2014). (2015).

6. Rey, J. M. M. \& de Febrer, M. T. Procedures for monitoring the right to food. Right to Food Handbooks (2014). 
7. Te Lintelo, D. J. H., Haddad, L. J., Leavy, J. \& Lakshman, R. Measuring the commitment to reduce hunger: $A$ hunger reduction commitment index. Food Policy 44, 115-128 (2014).

8. Gillespie, S., Haddad, L., Mannar, V., Menon, P. \& Nisbett, N. The politics of reducing malnutrition: Building commitment and accelerating progress. Lancet 382, 552-569 (2013).

9. Miller, M. A. Decentralizing Indonesian City Spaces as New 'Centers'. Int. J. Urban Reg. Res. 37, 834-848 (2013).

10. Harun, H., An, Y. \& Kahar, A. Implementation and challenges of introducing NPM and accrual accounting in Indonesian local government. Public Money Manag. 33, 383-388 (2013).

11. Azkha, N. Teori, Kuisioner \&Analisis Data Untuk Pemasaran Dan Perilaku Konsumen. J. Kebijak. Kesehat. Indones. 02, 171-179 (2013).

12. Hoey, L. \& Pelletier, D. L. Bolivia's multisectoral Zero Malnutrition Program: Insights on commitment, collaboration, and capacities. Food Nutr. Bull. 32, 70-81 (2011).

13. WFP \& Pangan, D. K. Peta Ketahanan dan Kerentanan Pangan Indonesia 2015: Versi Rangkuman. (2015).

14. Kementerian Kesehatan RI. Riset Kesehatan
Dasar. Kementerian Kesehatan RI (2013).

15. Tono, Juanda, B., Barus, B. \& Martianto, D. Kerentanan Pangan tingkat desa di Provinsi Nusa Tenggara Timur (village food vulnerability in East Nusa Tenggara). J.Gizi Pangan 11, 227236 (2016).

16. Boli, E. B., Baliwati, Y. F. \& Sukandar, D. Komitmen Politik dan Peluang Pengembangan Kebijakan Gizi Pemerintah Daerah Provinsi Nusa Tenggara Timur. Media Kesehat. Masy. Indones. 14, 351 (2018).

17. Fox, A. M., Balarajan, Y., Cheng, C. \& Reich, M. R. Measuring political commitment and opportunities to advance food and nutrition security: Piloting a rapid assessment tool. Health Policy Plan. 30, 566-578 (2015).

18. Pelletier, D. L. et al. Nutrition agenda setting, policy formulation and implementation: Lessons from the Mainstreaming Nutrition Initiative. Health Policy Plan. 27, 19-31 (2012).

19. Bryce, J., Coitinho, D., Darnton-Hill, I., Pelletier, D. \& Pinstrup-Andersen, P. Maternal and child undernutrition: effective action at national level. Lancet 371, 510-526 (2008).

20. Mejía Acosta, A. \& Haddad, L. The politics of success in the fight against malnutrition in Peru. Food Policy 44, 26-35 (2014). 